centrations of impurity atoms in semiconducting material. Other applications were also mentioned, such as following the progress of chemical reactions which proceed via a transient intermediate, and also the detailed structural information that can often be determined from the angular variation of the spectra in single crystals.

The discussion which followed the main papers was opened by Drs. D. H. Whiffen, C. A. Parker and D. J. Ferrett. One of the main questions raised was that of absolute calibration and reproducibility of results. It was suggested that the most accurate form of quantitative measurement was by comparison with the signal from a small amount of a standard sample placed in the same radio-frequency field. For work with free radicals, the use of auxiliary coils to increase the field around the standard specimen was mentioned, although the more general technique employing a substance such as ultramarine, which has its resonance slightly displaced from the freeelectron value, is probably to be preferred. The applications of the relatively less expensive lowresolution nuclear resonance were also described since, although this cannot give the group analysis of the high-resolution work, it can be applied to quantitative determinations of isotope concentrations for more than a hundred different nuclei.

It would appear that there are in fact three distinct types of resonance spectroscope that should be of considerable use to the chemist. The first is that employing very high-resolution nuclear magnetic resonance. This can not only distinguish different isotopes but also differentiate between various groups and bond-types of the same element, and thus provide a detailed structural analysis from a few grams of liquid. The disadvantage of this type of apparatus is purely practical, as a twelve-inch diameter magnet with a very homogeneous field is required, at a cost of several thousands of pounds. If detailed chemical information is not required, however, and only a quantitative determination of the different elements present is needed, then lowresolution nuclear resonance is quite sufficient, and relatively inexpensive magnets can be used. It is also easier to apply more sensitive means of detection to the low-resolution apparatus, and concentrations down to $10^{16}$ protons per gm. can be measured.

As distinct from both of these, an electronresonance spectroscope can be used wherever unpaired electrons occur in a chemical system. The sensitivity is very much greater than that of nuclear resonance, and the less expensive magnets can be employed. It should therefore prove a powerful and readily available tool for investigating such systems down to dilutions of $10^{-11}$ molar. It would appear that the main applications of this technique are going to be in the fields of free-radical and irradiation chemistry, and it will probably find as much use in the medical and biological sciences as in physical chemistry.

\title{
OBITUARY
}

\section{Mr. E. B. Wedmore, C.B.E.}

The name of Mr. E. B. Wedmore, whose death occurred at the age of eighty years on June 16, is widely known in two very different spheres. He was in a very real sense a pioneer in the development of research associations, and he was an apiarist of great repute. Mr. Wedmore can properly be described as the architect of the structure of the British Electrical and Allied Industries Research Association (E.R.A.), which is one of the largest co-operative research organizations in Great Britain at the present time.

Born at Bristol in 1876, Wedmore received his early education at private schools. His first scientific education at the University College of Bristol was followed by a short course in civil engineering at the Finsbury Technical College, and then by the full course in electrical engineering at that College.

$\mathrm{He}$ joined the Bristol Corporation Electricity Works in 1895 as an assistant, but returned to Finsbury Technical College during 1896-99 as a lecturer and demonstrator, gaining the City and Guilds Silver Medal in 1896. During 1899-1919 he was design engineer with the British ThomsonHouston Co., Ltd., in London and Rugby, and during this time he took out a number of patents, mainly for switchgear.

A shortage of certain materials essential to the electrical industry arose in 1917 as a result of sub. marine warfare, and in order to foster the devising of means to minimize the effects of this shortage, an Electrical Research Committee (E.R.C.) was set up under the regis of the British Electrical and Allied Manufacturers' Association and the Institution of
Electrical Engineers; this was the forerunner of the British Electrical and Allied Industries Research Association. Mr. Wedmore was appointed director of the earlier body in 1919, and he became director and secretary of its successor upon the incorporation of that body in 1920. This post he held up to the time of his retirement at the end of 1944. In 1938 he was appointed C.B.E. in recognition of his services.

Wedmore's qualities of character and mind proved to be admirably suited to the task of building up and developing the young research association. He was a good judge of men and quickly gathered about him a group of able engineers and scientists. Scientific judgment and inventiveness he possessed himself in a high degree, and he had an inspiring fertility of mind. With all these qualities was coupled an extraordinary business acumen.

Wedmore's own field of scientific interest was wide; it accommodated such diverse topics as colour photography and the making of models of fourdimensional 'objects' as seen in three-dimensional space. His major contributions were to the art of circuit breaking and to improvements in switchgear. Crucial observations of some of the basic phenomena of circuit breaking were made with a simple highspeed camera devised by Wedmore, and as an outcome of these experiments came the invention, jointly with Dr. Whitney, of the air-blast circuit breaker and of the oil-baffle switch. Wedmore was active in the field of international standardization, and was a member of a number of committees of the International Electro-Technical Commission. He attended the first meeting of the Conférence International des Grands Réseaux Electrique, which was held in Paris in 1921, and he was largely responsible 
for the establishment of the liaison committee of that conference, from which developed the present British National Committee.

Wedmore communicated a number of papers to the Institution of Electrical Engineers and he was awarded several of the major premiums of the Institution, namely, the John Hopkinson in 1915, the Institution Premium in 1918, and the Kelvin in 1929.

Wedmore was reticent in nature and somewhat austere in appearance. He was, however, under the surface, very human and generous and sympathetic to any in real trouble, and he had a deep sense of loyalty to colleagues. It is a tribute to Wedmore's insight and ability that he should have built up, as a pioneer, a successful co-operative research organization with little to guide him other than his own shrewd judgment and initiative.

J. GREIG

The death of $\mathrm{Mr}$. E. B. Wedmore has removed a well-known and greatly respected personality from bee-keeping circles. Despite his heavy professional responsibilities when director of the British Electrical and Allied Industries Research Association, $\mathrm{Mr}$. Wedmore managed to find time to practise beekeeping, to which he applied his scientific training and research experience. Since his retirement a few years ago, beekeeping research had occupied an increasing proportion of his time and he was always eager to discuss new results and ideas and to help beekeepers and research workers in any way that he could.

In 1944 the Beekeeping Standards Committee of the British Standards Institution was formed, and $\mathrm{Mr}$. Wedmore was the natural choice for its first chairman, a position he held with great distinction until his death. He also served on other committees of the Institution which dealt with the standardization of honey tins, honey jars, etc.

For many years $\mathrm{Mr}$. Wedmore was a member of the Apis Club, several county beekeepers' associations and of the British Beekeepers' Association, of which he was president in 1946. He was, for some time, chairman of the Research Committee of the British Beekeepers' Association, and was an active member of the Council of the Bee Research Association since its formation in 1949. He was responsible for a number of the Association's researches which were carried out with the co-operation of beekeepers, notably on methods of management of colonies and on queen introduction.

$\mathrm{He}$ was also interested in establishing better standards for honey in Britain, and his re-examination of earlier work on the chemical and physical properties of honey led to new tables relating refractive index to water content. Further papers on the accurate determination of the water content of honeys were in preparation at the time of his death.

Mr. Wedmore's books, "A Manual of Beekeeping" and "The Ventilation of Bee-Hives", together with his booklet, "Successful Bee-keeping", will undoubtedly continue to be used by beekeepers for many years to come.

Although rather shy and reserved, Mr. Wedmore gave much time to helping other beekeepers by lecturing and in other ways. His lectures contained a great deal of original, constructive thought. He was always willing to reconsider his own views in the light of new work and was foremost in efforts to encourage beekeepers to do the same.

\section{G. Butler}

\section{NEWS and VIEWS}

\section{Linnean Gold Medal : $\quad$ Prof. W. H. Lang, F.R.S.}

THE award by the Linnean Society of London of the Linnean Gold Medal to Prof. W. H. Lang will be regarded with much satisfaction by botanists, and especially palæobotanists, throughout the world. Although in the earlier part of his scientific career his attention was mainly directed to the Pteridophyta and Bryophyta, he later concentrated on investigation of eaily Devonian plants. During the time he taught in the University of Glasgow his contacts with Robert Kidston inspired him with an interest in palæozoic plants and led to that fruitful col. laboration with Kidston in the description of the Devonian plants found in the Rhynie Chert in Aberdeenshire. The results of this investigation, published in the Transactions of the Royal Society of Edinburgh between 1917 and 1921, have had a profound influence on our ideas about the evolution of vascular plants, perhaps more than any other palæobotanical discovery of this century. Prof. Lang has made many notable contributions to our knowledge of the morphology of the Pteridophyta and, after collaboration ceased with Kidston's death in 1924, he has continued to investigate early Devonian plants and has shown that important information can be obtained from apparenty unpromising and fragmentary plant remains. In collaboration with Dr. Cookson, of Australia, he described the Silurian plants which are found in Australia, the earliest indubitable land plants. His published work, like that of Kidston, has always been marked by meticulous attention to accuracy and he rarely, if ever, makes a statement about a plant which is not clearly demonstiatued by photographic reproduction. He has carefully avoided entering the field of speculative morphology, to which the discovery of the Rhynie plants added such a potent stimulus.

\section{Pure Mathematics in the Imperial College, London:} Prof. W. K. Hayman, F.R.S.

Dr. Walter K. Hayman, reader in analysis at the University of Exeter, has been appointed to a newly created University chair in pure mathematics at the Imperial College of Science and Technology, London. Dr. Hayman is a brilliant mathematician with an international reputation in his own field, and the value of the contributions which he has made in this field has been recognized by his election at the early age of thirty to a fellowship of the Royal Society. Since graduating in 1946, he has published a number of papers, largely concerned with the behaviour of the maximum modulus of an analytic function which satisfies certain specified conditions. Perhaps the most striking of his results relate to the celebrated conjectures of Bieberbach and Wiman. On one hand he has proved that, if a given function $f(z)=z+a_{2} z^{2}+\ldots$ is schlicht in $|z|<1$, then Bieberbach's conjecture that $\left|a_{n}\right| \leqslant n$ does hold for 